\title{
Recall of anti-tobacco advertising and information, warning labels and news stories in a national sample of Aboriginal and Torres Strait Islander smokers
}

T elevision advertisements and warning labels on tobacco products are the most commonly cited sources of information on the dangers of smoking., ${ }^{1,2}$ There is good evidence that messages about the harms of smoking increase knowledge, worry about health risks, attempts to quit, and even quit success. ${ }^{3-7}$ These messages aim to either change pro-smoking attitudes and intentions or strengthen those that support quitting. ${ }^{8}$

Smoking is the leading cause of sickness and death among Aboriginal and Torres Strait Islander peoples. ${ }^{9}$ To tackle this, funding was established in 2009 for community-led programs that raise awareness, provide education and challenge norms about smoking..$^{10}$ Australia also launched its first national Indigenous AntiSmoking Campaign ("Break the Chain") in March 2011. ${ }^{11}$ These targeted programs ran alongside the National Tobacco Campaign, state and territory campaigns, and other sources of information, such as news media. In addition, plain packaging of tobacco products, with new and larger warning labels, was mandated from 1 December 2012. ${ }^{12}$

Some experts doubt the effectiveness of mainstream messages in reducing smoking among Aboriginal and Torres Strait Islander peoples. ${ }^{13}$ While culturally relevant messages are preferred ${ }_{1}^{14}$ mainstream media campaigns achieve high recall, ${ }^{15-17}$ including in remote areas. ${ }^{17,18}$ Here, we describe recall of anti-tobacco advertising and information (mainstream and targeted), pack warning labels and news stories among Aboriginal and Torres Strait Islander smokers, and assess the association of these messages with attitudes that support quitting.

\section{Abstract}

Objectives: To describe recall of anti-tobacco advertising (mainstream and targeted), pack warning labels, and news stories among a national sample of Aboriginal and Torres Strait Islander smokers, and to assess the association of these messages with attitudes that support quitting, including wanting to quit.

Design, setting and participants: A quota sampling design was used to recruit participants from communities served by 34 Aboriginal communitycontrolled health services and one community in the Torres Strait. We surveyed 1643 Aboriginal and Torres Strait Islander smokers from April 2012 to October 2013.

Main outcome measures: Frequency of recall of advertising and information, warning labels and news stories; recall of targeted and local advertising; attitudes about smoking and wanting to quit.

Results: More smokers recalled often noticing warning labels in the past month (65\%) than recalled advertising and information (45\%) or news stories (24\%) in the past 6 months. When prompted, most ( $82 \%$ ) recalled seeing a television advertisement. Just under half (48\%) recalled advertising that featured an Aboriginal or Torres Strait Islander person or artwork (targeted advertising), and 16\% recalled targeted advertising from their community (local advertising). Frequent recall of warning labels, news stories and advertising was associated with worry about health and wanting to quit, but only frequent advertising recall was associated with believing that society disapproves of smoking. The magnitude of association with relevant attitudes and wanting to quit increased for targeted and local advertising.

Conclusions: Strategies to tackle Aboriginal and Torres Strait Islander smoking should sustain high levels of exposure to anti-tobacco advertising, news stories and warning labels. More targeted and local information may be particularly effective to influence relevant beliefs and subsequently increase quitting.

\section{Methods}

\section{Survey design and participants}

The Talking About The Smokes (TATS) project surveyed 1643 current smokers from April 2012 to October 2013 (Wave 1, or baseline), and has been described in detail elsewhere ${ }^{19,20}$ Briefly, we used a quota sampling design to recruit participants from communities served by 34 Aboriginal community-controlled health services (ACCHSs) and one community in the Torres Strait (project sites), which were selected based on the population distribution of Aboriginal and Torres Strait Islander people by state or territory and remoteness. In most sites (30/35), we aimed to interview a sample of 50 smokers or recent quitters (ex-smokers who had quit $\leqslant 12$ months previously), with even numbers of men and women, and people aged $18-34$ and $\geqslant 35$ years. The sample size was doubled in four large city sites and in the Torres Strait community. People were excluded if they did not identify as Aboriginal or Torres Strait Islander, were under 18 years of age, were not usual residents of the area, were staff of the ACCHS, were unable to complete the survey in English if there was no interpreter available, or if the quota for the relevant age-sex-smoking category had been filled. In each site, different locally determined methods were used 
to collect a representative, albeit nonrandom, sample.

Interviews were conducted face to face by trained interviewers, almost all of whom were members of the local Aboriginal and Torres Strait Islander community. The survey, entered directly onto a computer tablet, took 30-60 minutes to complete. A single survey of health service activities was also completed for each project site.

The baseline sample closely matched the sample distribution of the 2008 National Aboriginal and Torres Strait Islander Social Survey (NATSISS) by age, sex, jurisdiction and remoteness, and by number of cigarettes smoked per day for current daily smokers. However, there were inconsistent differences in some socioeconomic indicators: our sample had higher proportions of unemployed people, but also higher proportions who had completed Year 12 and who lived in more advantaged areas. ${ }^{19}$

The project was approved by three Aboriginal human research ethics committees (HRECs) and two HRECs with Aboriginal subcommittees: Aboriginal Health \& Medical Research Council Ethics Committee, Sydney; Aboriginal Health Research Ethics Committee, Adelaide; Central Australian HREC, Alice Springs; HREC for the Northern Territory Department of Health and Menzies School of Health Research, Darwin; and the Western Australian Aboriginal Health Ethics Committee, Perth.

\section{Questions on health information exposure}

As the TATS project is part of the International Tobacco Control Policy Evaluation Project (ITC Project), survey questions were based on ITC Project survey questions and are presented in Appendix 1. How often respondents noticed warning labels (in the past month), anti-tobacco news stories (in the past 6 months) and antitobacco advertising or information (in the past 6 months) was assessed on a five-point scale ranging from "never" to "very often", which was later collapsed to three categories (never, sometimes, often).
Smokers who said they had never noticed advertising or information (hereafter collectively referred to as advertising) in the past 6 months were not asked further related questions. Smokers who had noticed advertising were asked whether it was on: television, radio, the internet, outdoor billboards, newspapers or magazines, shops or stores, pamphlets, and posters in various locations (yes or no). Those who recalled noticing advertising in the past 6 months were also asked whether any had featured an Aboriginal or Torres Strait Islander person or artwork ("targeted advertising") and, if so, whether any featured an Aboriginal or Torres Strait Islander person or artwork from the local community ("local advertising"). We combined these responses to create the variable "type of advertising", which categorised smokers as having: never noticed any advertising, noticed mainstream (but no targeted) advertising, noticed some targeted (but no local) advertising, or noticed some local advertising.

\section{Main outcome measures and covariates}

There were four main outcomes: believing smoking is dangerous to others ("agree" or "strongly agree" that cigarette smoke is dangerous to both non-smokers and children), being very worried that smoking will damage the smoker's own health in the future, agreeing that mainstream society disapproves of smoking, and wanting to quit. Additional analyses were conducted on forgoing cigarettes because of warning labels.

Covariates included daily or nondaily smoking status and key sociodemographic indicators (sex, age, identification as Aboriginal and/or Torres Strait Islander, labour force status, education, remoteness and area-level disadvantage). We also assessed for variation according to tobacco control activity that had occurred at the project site over the previous year (whether there were dedicated tobacco control resources, and the number of media used to communicate anti-tobacco advertising), which was determined in the project site survey.
We also assessed differences in warning label recall before and after plain packaging was mandated (1 December 2012), treating the 3-month phase-in period as "before".

\section{Statistical analyses}

Logistic regression was used to assess: (i) variation in health information recall (often $\mathrm{v}$ sometimes or never) by daily smoking status, sociodemographic variables, and tobacco control activity at the project site; (ii) the association between health information recall and the four main outcome measures; and (iii) variation in warning label recall and outcomes before and after plain packaging was mandated. Stata 13 (StataCorp) survey [SVY] commands were used to adjust for the sampling design, identifying the 35 project sites as clusters and the quotas (based on age, sex and smoking status) as strata. ${ }^{21}$

Data for health information recall were excluded for less than $2 \%$ of participants due to missing or refused responses, and for less than $2 \%$ due to "don't know" responses. Questions about recall of warning labels were not asked of those who had not smoked in the past month $(n=44)$, nor those surveyed at the first project site $(n=26)$, after which questions were modified. These participants were therefore excluded from logistic regression analyses, which controlled for recall of each other type of health information, survey month (collapsed into 2-month blocks), daily smoking status and other sociodemographic covariates. Regression analyses for wanting to quit excluded a further $4.8 \%$ of smokers who responded "don't know" to this question.

\section{Results}

\section{Recall of health information}

Of smokers who were asked about warning labels, 65\% (1015/1557) said they had often noticed warning labels in the past month (Box 1). This was higher than the proportion of all smokers who recalled often noticing anti-tobacco advertising (45\%; $730 / 1606)$ or news stories (24\%; $386 / 1601)$ in the past 6 months. 
Frequent recall of health information was similar for daily and non-daily smokers (Appendix 2). Fewer men than women reported often noticing warning labels (odds ratio [OR], 0.68 ; 95\% CI, 0.51-0.90) and news stories (OR, 0.71; 95\% CI, 0.51-1.00). While smokers from remote areas were less likely than those in major cities to recall often noticing advertising (OR, 0.56; 95\% CI, 0.37-0.84), they were more likely to recall often noticing news stories (OR, 1.81; 95\% CI, 1.18-2.79) and did not differ for recall of warning labels. Being from an area where the health service used a greater range of advertising media was associated with noticing it more often, with ORs increasing from 2.02 (95\% CI, 1.15-3.57) for 5-8 media to 3.17 (95\% CI, 1.84-5.46) for 9-12 media, compared with areas that used four or fewer media.

\section{Associations with attitudes and wanting to quit}

Recall of warning labels, advertising and news stories was positively associated with being very worried about future health and wanting to quit (Box 2). Only advertising recall was positively associated with believing society disapproves of smoking. For each outcome, the magnitude of ORs increased for those who recalled more targeted and local advertising, although this association was only significant for believing cigarette smoke is dangerous to others and wanting to quit.

\section{Outcomes for warning labels before and after plain packaging}

Compared with smokers surveyed in the period before plain packaging, those surveyed after its introduction were similarly likely to recall noticing warning labels but had higher odds for believing the labels made them more likely to quit (OR, 1.37; 95\% CI 1.02-1.82) (Appendix 3). Smokers who had noticed warning labels in the past month were more likely to say these labels led them to forgo at least one cigarette after plain packaging compared with before it $(\mathrm{OR}$ $1.54 ; 95 \%$ CI, 1.14-2.09). Further, those who said warning labels led them to forgo at least one cigarette were more

\section{Exposure to health information in a national sample of Aboriginal and Torres Strait} Islander smokers*

Health information exposure variables $\%$ (frequency) $^{\dagger}$

Warning labels (in past month)

How often have you noticed the warning labels on packs your smokes are sold in?

Never

$11 \%(164)$

Almost never or sometimes

$24 \%(378)$

Often or very often

$65 \%(1015)$

Have the warning labels stopped you from having a smoke when about to?

Never noticed warning labels

$10 \%(164)$

Noticed warning labels but never stopped

$55 \%(887)$

Noticed warning labels and stopped at least once

$34 \%(550)$

News stories (in past 6 months)

How often have you seen or heard a news story about smoking or quitting?

Never

$30 \%(477)$

Almost never or sometimes

$46 \%(738)$

Often or very often

$24 \%(386)$

\section{Advertising and information (in past 6 months)}

How often have you noticed anti-tobacco advertising or information?

Never

$15 \%(241)$

Almost never or sometimes

$40 \%(635)$

Often or very often

$45 \%(730)$

Noticed any targeted advertising

Yes

$48 \%(783)$

No or never noticed advertising

$46 \%(745)$

Don't know

$6 \%(96)$

Noticed any local advertising

Yes

$16 \%(258)$

No or never noticed mainstream or targeted advertising

$74 \%(1195)$

Don't know

$11 \%(171)$

Did you notice advertising or information: ${ }^{\ddagger}$

On television

$82 \%(1327)$

On the radio

$43 \%(690)$

On the internet, including social media sites

$25 \%(390)$

On outdoor billboards

$45 \%(706)$

In newspapers or magazines

$47 \%(751)$

$43 \%(679)$

$55 \%(877)$

In leaflets or pamphlets

Posters or displays at local health service

$74 \%(1186)$

Posters or displays at other Aboriginal or Torres Strait Islander organisation

$67 \%(1051)$

Posters or displays at local festival or community event

$59 \%(921)$

* Results are from the Talking About The Smokes baseline sample of current smokers ( $n=1643$, or $n=1573$ for questions regarding recall of warning labels). $†$ Except where specified (for targeted and local advertising), percentages and frequencies exclude refused and "don't know" responses, which accounts for differences in the total. ‡Results are percentages of all smokers, including those who had never seen advertising or information in the past 6 months.

likely to want to quit (OR, 3.73; 95\% CI, 2.63-5.29) (data not shown).

\section{Discussion}

\section{Advertising and information}

We found high levels of recall of antitobacco advertising and information, particularly for television campaigns and local health promotion materials, which is likely to have been boosted by the community-led tobacco control activity that occurred over the survey period. However, even with this heightened activity, smokers from remote areas were less likely to say they often noticed advertising, consistent with trends for national mass media exposure. ${ }^{22}$ Recall of mass media advertising has been shown to increase 
2 Association of health information exposure with attitudes in a national sample of Aboriginal and Torres Strait Islander smokers*

\begin{tabular}{|c|c|c|c|c|c|c|c|c|}
\hline & \multicolumn{2}{|c|}{$\begin{array}{l}\text { Believe smoking is dangerous } \\
\text { to others }\end{array}$} & \multicolumn{2}{|c|}{$\begin{array}{l}\text { Very worried smoking will } \\
\text { damage own health }\end{array}$} & \multicolumn{2}{|c|}{$\begin{array}{l}\text { Believe mainstream society } \\
\text { disapproves of smoking }\end{array}$} & \multicolumn{2}{|c|}{$\begin{array}{l}\text { Want to quit } \\
\text { smoking }\end{array}$} \\
\hline & $\begin{array}{c}\% \\
\text { (frequency) }^{\dagger}\end{array}$ & $\begin{array}{c}\text { AOR } \\
(95 \% \mathrm{Cl})^{\ddagger}\end{array}$ & $\begin{array}{c}\% \\
\text { (frequency) }^{\dagger}\end{array}$ & $\begin{array}{c}\text { AOR } \\
(95 \% \mathrm{Cl})^{\ddagger}\end{array}$ & $\begin{array}{c}\% \\
\text { (frequency) }^{\dagger}\end{array}$ & $\begin{array}{c}\text { AOR } \\
(95 \% \mathrm{Cl})^{\ddagger}\end{array}$ & $\begin{array}{c}\% \\
\text { (frequency) }^{\dagger} \\
\end{array}$ & $\begin{array}{c}\text { AOR } \\
(95 \% \mathrm{Cl})^{\ddagger}\end{array}$ \\
\hline $\begin{array}{l}\text { Noticed warning labels } \\
\text { (in past month) }\end{array}$ & & $P<0.001$ & & $P<0.001$ & & $P=0.45$ & & $P<0.001$ \\
\hline Never & $77 \%(126)$ & 1.0 & $14 \%(22)$ & 1.0 & $58 \%(95)$ & 1.0 & $45 \%(71)$ & 1.0 \\
\hline Sometimes & $86 \%(325)$ & $\begin{array}{c}1.54 \\
(0.93-2.56)\end{array}$ & $20 \%(75)$ & $\begin{array}{c}1.41 \\
(0.81-2.44)\end{array}$ & $55 \%(209)$ & $\begin{array}{c}1.01 \\
(0.67-1.54)\end{array}$ & $58 \%(204)$ & $\begin{array}{c}1.31 \\
(0.82-2.07)\end{array}$ \\
\hline Often & $94 \%(953)$ & $\begin{array}{c}3.56 \\
(2.16-5.86)\end{array}$ & $44 \%(442)$ & $\begin{array}{c}3.44 \\
(2.14-5.53)\end{array}$ & $64 \%(650)$ & $\begin{array}{c}1.21 \\
(0.80-1.81)\end{array}$ & $78 \%$ (755) & $\begin{array}{c}2.90 \\
(1.85-4.52)\end{array}$ \\
\hline $\begin{array}{l}\text { Noticed news stories } \\
\text { (in past } 6 \text { months) }\end{array}$ & & $P=0.12$ & & $P=0.002$ & & $P=0.12$ & & $P=0.03$ \\
\hline Never & $90 \%(427)$ & 1.0 & $25 \%(118)$ & 1.0 & 64\% (306) & 1.0 & $59 \%(271)$ & 1.0 \\
\hline Sometimes & $91 \%(668)$ & $\begin{array}{c}0.58 \\
(0.35-0.97)\end{array}$ & $34 \%(250)$ & $\begin{array}{c}1.56 \\
(1.16-2.08)\end{array}$ & $59 \%(438)$ & $\begin{array}{c}0.75 \\
(0.56-1.00)\end{array}$ & $71 \%(491)$ & $\begin{array}{c}1.40 \\
(1.07-1.82)\end{array}$ \\
\hline Often & 93\% (359) & $\begin{array}{c}0.67 \\
(0.37-1.24)\end{array}$ & 49\% (187) & $\begin{array}{c}1.84 \\
(1.30-2.61)\end{array}$ & $66 \%(254)$ & $\begin{array}{c}0.73 \\
(0.51-1.05)\end{array}$ & $81 \%$ (297) & $\begin{array}{c}1.61 \\
(1.05-2.47)\end{array}$ \\
\hline $\begin{array}{l}\text { Noticed advertising } \\
\text { (in past } 6 \text { months) }\end{array}$ & & $P=0.004$ & & $P<0.001$ & & $P<0.001$ & & $P=0.002$ \\
\hline Never & $82 \%(197)$ & 1.0 & $18 \%(42)$ & 1.0 & $58 \%(139)$ & 1.0 & $48 \%(112)$ & 1.0 \\
\hline Sometimes & $91 \%(580)$ & $\begin{array}{c}2.26 \\
(1.31-3.88)\end{array}$ & 29\% (179) & $\begin{array}{c}1.10 \\
(0.70-1.73)\end{array}$ & $56 \%(356)$ & $\begin{array}{c}1.08 \\
(0.74-1.57)\end{array}$ & $68 \%(403)$ & $\begin{array}{c}1.57 \\
(1.12-2.18)\end{array}$ \\
\hline Often & $94 \%(684)$ & $\begin{array}{c}2.78 \\
(1.47-5.26)\end{array}$ & $47 \%(342)$ & $\begin{array}{c}2.02 \\
(1.29-3.17)\end{array}$ & $70 \%$ (510) & $\begin{array}{c}2.07 \\
(1.31-3.27)\end{array}$ & 79\% (548) & $\begin{array}{c}2.17 \\
(1.42-3.31)\end{array}$ \\
\hline $\begin{array}{l}\text { Type of advertising } \\
\text { (in past } 6 \text { months) }^{f}\end{array}$ & & $P=0.006$ & & $P=0.25$ & & $P=0.60$ & & $P<0.001$ \\
\hline $\begin{array}{l}\text { Never noticed any } \\
\text { advertising }\end{array}$ & $82 \%(197)$ & 1.0 & $18 \%(42)$ & 1.0 & $58 \%(139)$ & 1.0 & $48 \%(112)$ & 1.0 \\
\hline $\begin{array}{l}\text { Noticed mainstream } \\
\text { (but no targeted) } \\
\text { advertising }\end{array}$ & $91 \%(522)$ & $\begin{array}{c}1.94 \\
(1.09-3.46)\end{array}$ & $32 \%(181)$ & $\begin{array}{c}1.00 \\
(0.62-1.60)\end{array}$ & $60 \%(345)$ & $\begin{array}{c}1.00 \\
(0.67-1.48)\end{array}$ & $65 \%(354)$ & $\begin{array}{c}1.27 \\
(0.91-1.78)\end{array}$ \\
\hline $\begin{array}{l}\text { Noticed some } \\
\text { targeted (but no local) } \\
\text { advertising }\end{array}$ & $93 \%$ (489) & $\begin{array}{c}2.58 \\
(1.39-4.80)\end{array}$ & $43 \%(224)$ & $\begin{array}{c}1.15 \\
(0.72-1.83)\end{array}$ & $66 \%(347)$ & $\begin{array}{c}1.13 \\
(0.74-1.74)\end{array}$ & 77\% (388) & $\begin{array}{c}1.99 \\
(1.30-3.04)\end{array}$ \\
\hline $\begin{array}{l}\text { Noticed some local } \\
\text { advertising }\end{array}$ & $95 \%(245)$ & $\begin{array}{c}3.63 \\
(1.58-8.38) \\
\end{array}$ & $44 \%(112)$ & $\begin{array}{c}1.34 \\
(0.79-2.27) \\
\end{array}$ & $66 \%(170)$ & $\begin{array}{c}1.24 \\
(0.79-1.97) \\
\end{array}$ & $84 \%(202)$ & $\begin{array}{c}2.88 \\
(1.76-4.72)\end{array}$ \\
\hline
\end{tabular}

with broadcast intensity, ${ }^{23-25}$ which is fundamental to achieving good reach among smokers of low socioeconomic status. ${ }^{6,25-27}$ Broadcast intensity is also important for influencing quitting activity and success. 5,6,22,25,28,29

It is notable that targeted and local advertising was associated with higher levels of motivation to quit, a novel finding as far as we are aware. In part, targeted campaigns may be more memorable purely because of the interest in their targeted or local nature, ${ }^{30}$ which could be expected to weaken the observed relationship with wanting to quit. On the contrary, our results show the association increased in magnitude for recall of more targeted and local information, which suggests it is more potent than mainstream advertising. This finding is supported by analyses presented elsewhere in this supplement. ${ }^{31}$ While it is possible that the observed relationship could be due to higher exposure to all types of advertising, it remained significant irrespective of how often advertising was noticed.

Aboriginal and Torres Strait Islander peoples perceive targeted messages to be more relevant and effective, ${ }^{14,15,30}$ which may affect the influence of these messages on relevant attitudes. Among Maori people in New
Zealand, culturally relevant campaigns have been shown to prompt discussions about smoking ${ }^{32}$ - an indirect effect of advertising that increases interest in quitting. ${ }^{33}$ While there is clear justification for targeted messages, together with emerging evidence regarding their benefit, consideration must also be given to whether this strategy is an effective use of scarce resources. ${ }^{34}$

Elsewhere, attitudes and intentions have been found to be most strongly influenced by advertising that evokes an emotional response, such as graphic or story-based messages. ${ }^{6,25,35}$ Such messages are rated 
highly by Aboriginal and Torres Strait Islander people and non-Indigenous Australians alike, ${ }^{14}$ and may also be an effective way to reduce disparities in quitting. ${ }^{36}$ How to best balance mainstream and targeted (including locally led) advertising will be an important area for future research.

\section{Warning labels}

We found that forgoing cigarettes was strongly associated with wanting to quit, as has been found in other settings, ${ }^{37,38}$ and that smokers were more likely to forgo cigarettes in the period after plain packaging was mandated than before. Although our before and after samples were not in any way random, the evidence is supportive of health warnings and plain packaging playing a role in maintaining concern about smoking. This is one of the aims of Australia's plain packaging legislation, which increased the size of graphic warning labels, stripped all branding and regulated a drab brown pack colour. ${ }^{12}$

There is recent evidence that plain packaging increases the salience and effectiveness of health warnings..$^{39-41}$ Our findings confirm these findings in a minority population with a high smoking prevalence. Further, our finding that warning label recall was not socially patterned adds to scarce evidence on the socioeconomic impacts of graphic pack warning labels, which has been identified as an international priority for tobacco control research. ${ }^{6,42}$

\section{News stories}

Frequent recall of news stories was related to higher levels of worry about health and interest in quitting, which supports previous findings that news items can complement paid sources of communication. ${ }^{6,43}$ We found no evidence of a social gradient in recall of news stories; in fact, they were more likely to be noticed often by smokers from remote areas. Online platforms to share and discuss news could play an important role here, and have been used effectively for Aboriginal tobacco control news and advocacy efforts. ${ }^{44}$ Local stories and those about leaders and other role models may be particularly influential. ${ }^{45,46}$

\section{Strengths and limitations}

This article draws on data from a broadly representative national sample of Aboriginal and Torres Strait Islander smokers. The size of the sample has enabled us to consider subgroup analyses based on socioeconomic indicators and other participant characteristics, including remoteness of residence. The frequency at which health promotional materials were recalled is likely to have been inflated by biased recruitment of project sites that prioritised tobacco control and of participants who were more connected to the health service. Although this means we cannot generalise results about how often different types of advertising and information were recalled, it does not compromise the findings on whether more frequent recall is associated with relevant attitudes and intentions.

The main limitation of our study is its reliance on self-report of awareness. It does not incorporate more objective media market data, as these would not capture some of the local activity and would therefore have been a limited source of information beyond the main media markets. Awareness can be affected by opportunity for exposure, the potency of the material, and the openness of the individual to the message. While it is impossible to separate these entirely, it is possible to infer likely relative contributions. For example, warning labels on packs are roughly equally available (albeit affected by levels of consumption) and are of largely fixed (standardised) potency. Thus, differences in recall and reactions can be largely attributed to the openness of the individual to the label's message. When assessing associations with attitudes or intentions, we adjusted for noticing other types of health information (to control for variability due to openness) and for socioeconomic indicators (to control for variability due to opportunity for exposure), with the rationale that associations independent of these influences were a better assessment of potency. However, campaign effects are difficult to disentangle from other tobacco control efforts and contextual factors, ${ }^{3}$ particularly when using cross-sectional data. As such, a multivariable model that considers these factors has been reported in detail elsewhere for the outcome of wanting to quit. ${ }^{31}$

Finally, we report adjusted analyses, which necessarily exclude a small proportion of smokers who declined to answer questions, answered "don't know", had not smoked in the past month or were surveyed at the first project site. While it is possible that the excluded participants differ from those who were included, the same pattern of results was observed for unadjusted associations (where there were fewer exclusions) and where outcomes with a high percentage of "don't know" responses (eg, wanting to quit) were repeated with "don't know" recoded as "no".

With these limitations in mind, we found a clear link between more frequent recall of health information and attitudes that support quitting, including wanting to quit. Further research is required to assess whether more targeted information is better able to tap into relevant beliefs and subsequently increase quitting.

Acknowledgements: The full list of acknowledgements is available in Appendix 4.

Competing interests: No relevant disclosures.

Provenance: Not commissioned; externally peer reviewed.

Received 22 Nov 2014, accepted 20 Mar 2015.

1 Hammond D, Fong GT, McNeill A, et al. Effectiveness of cigarette warning labels in informing smokers about the risks of smoking: findings from the International Tobacco Control (ITC) Four Country Survey. Tob Control 2006; 15 Suppl 3: iii19-iii25.

2 Miller CL, Quester PG, Hill DJ, Hiller JE. Smokers' recall of Australian graphic cigarette packet warnings \& awareness of associated health effects, 2005-2008. BMC Public Health 2011; 11: 238.

3 Bala MM, Strzeszynski L, Topor-Madry $\mathrm{R}$, Cahill K. Mass media interventions for smoking cessation in adults. Cochrane Database Syst Rev 2013; (6): CD004704.

4 Rennen E, Nagelhout GE, van den Putte B, et al. Associations between tobacco control policy awareness, social acceptability of smoking and smoking cessation. Findings from the International 
Tobacco Control (ITC) Europe Surveys. Health Educ Res 2014; 29: 72-82.

5 Wakefield MA, Bowe SJ, Durkin SJ, et al. Does tobacco-control mass media campaign exposure prevent relapse among recent quitters? Nicotine Tob Res 2013; 15: 385-392.

6 Hammond D, Wakefield M, Durkin S, Brennan E. Tobacco packaging and mass media campaigns: research needs for Articles 11 and 12 of the WHO Framework Convention on Tobacco Control. Nicotine Tob Res 2013; 15: 817-831.

7 Partos TR, Borland R, Yong HH, et al. Cigarette packet warning labels can prevent relapse: findings from the International Tobacco Control 4-Country policy evaluation cohort study. Tob Control 2012; 22: e43-e50.

8 Fishbein M, Yzer MC. Using theory to design effective health behavior interventions. Commun Theory 2003; 13: 164-183.

9 Vos T, Barker B, Stanley L, et al. The burden of disease and injury in Aboriginal and Torres Strait Islander peoples 2003. Brisbane: School of Population Health, University of Queensland, 2007.

10 Council of Australian Governments. National Partnership Agreement on Closing the Gap in Indigenous health outcomes. Canberra: COAG, 2009.

11 Australian Government Department of Health. Indigenous Anti-Smoking Campaign: Break the Chain. Quantitative campaign effectiveness: research - executive summary October 2011. Canberra: Commonwealth of Australia, 2013. http://www.quitnow.gov.au/internet/quitnow/ publishing.nsf/Content/btc-indsurvey-execsumm (accessed Apr 2015).

12 Australian Government. Tobacco Plain Packaging Act 2011.

13 Paul CL, Turon H, Bonevski B, et al. A crosssectional survey of experts' opinions about the relative effectiveness of tobacco control strategies for the general population versus disadvantaged groups: what do we choose in the absence of evidence? BMC Public Health 2013; 13: 1144.

14 Stewart HS, Bowden JA, Bayly MC, et al. Potential effectiveness of specific anti-smoking mass media advertisements among Australian Indigenous smokers. Health Educ Res 2011; 26 961-975.

15 Gould GS, McEwen A, Watters T, et al. Should antitobacco media messages be culturally targeted for Indigenous populations? A systematic review and narrative synthesis. Tob Control 2013; 22: e7.

16 Murphy M, Mee V. The impact of the National Tobacco Campaign on Indigenous communities: a study in Victoria. In: Hassard K, editor. Australia's National Tobacco Campaign: evaluation report: vol. 1. Canberra: Department of Health and Aged Care, 1999

17 Boyle T, Shepherd CC, Pearson G, et al. Awareness and impact of the 'Bubblewrap' advertising campaign among Aboriginal smokers in Western Australia. Tob Control 2010; 19: 83-86.
18 Ivers R, Castro A, Parfitt D, et al. Television and delivery of health promotion programs to remote Aboriginal communities. Health Promot J Austr 2005; 16: 155-158.

19 Thomas DP, Briggs VL, Couzos S, et al. Research methods of Talking About The Smokes: an International Tobacco Control Policy Evaluation Project study with Aboriginal and Torres Strait Islander Australians. Med J Aust 2015; 202 (10 Suppl): S5-S12.

20 Couzos S, Nicholson AK, Hunt JM, et al. Talking About The Smokes: a large-scale, communitybased participatory research project. Med I Aust 2015; 202 (10 Suppl): S13-S19.

21 StataCorp. Stata survey data reference manual: release 13. College Station, Tex: StataCorp, 2013. http://www.stata.com/manualsl3/svy.pdf (accessed Apr 2015).

22 Wakefield MA, Spittal MJ, Yong HH, et al. Effects of mass media campaign exposure intensity and durability on quit attempts in a population-based cohort study. Health Educ Res 2011; 26: 988-997.

23 Richardson S, McNeill A, Langley TE, et al. The impact of televised tobacco control advertising content on campaign recall: evidence from the International Tobacco Control (ITC) United Kingdom Survey. BMC Public Health 2014; 14: 432

24 Dunlop SM, Perez D, Cotter T. The natural history of antismoking advertising recall: the influence of broadcasting parameters, emotional intensity and executional features. Tob Control 2014; 23: 215-222.

25 Durkin S, Brennan E, Wakefield M. Mass media campaigns to promote smoking cessation among adults: an integrative review. Tob Control 2012; 21: 127-138.

26 Hill D, Carroll T. Australia's National Tobacco Campaign. Tob Control 2003; 12: ii9-iil4.

27 Niederdeppe J, Farrelly MC, Nonnemaker J, et al. Socioeconomic variation in recall and perceived effectiveness of campaign advertisements to promote smoking cessation. Soc Sci Med 2011; 72 : 773-780.

28 Farrelly MC, Duke JC, Davis KC, et al. Promotion of smoking cessation with emotional and/or graphic antismoking advertising. Am J Prev Med 2012; 43: 475-482.

29 Dunlop S, Cotter T, Perez D, Wakefield, M. Televised antismoking advertising: effects of level and duration of exposure. Am J Public Health 2013; 103: e66-e73.

30 Campbell MA, Finlay S, Lucas K, et al. Kick the habit: a social marketing campaign by Aboriginal communities in NSW. Aust J Prim Health 2014; 20 : 327-333.

31 Nicholson AK, Borland R, Davey ME, et al. Predictors of wanting to quit in a national sample of Aboriginal and Torres Strait Islander smokers. Med J Aust 2015; 202 (10 Suppl): S26-S32.

32 Grigg M, Waa A, Bradbrook SK. Response to an indigenous smoking cessation media campaign it's about whānau. Aust N Z J Public Health 2008; 32: 559-564.
33 Dunlop SM, Cotter T, Perez D. When your smoking is not just about you: antismoking advertising, interpersonal pressure, and quitting outcomes. J Health Commun 2014; 19: 41-56.

34 Hornik RC, Ramirez AS. Racial/ethnic disparities and segmentation in communication campaigns. Am Behav Sci 2006; 49: 868-884.

35 National Cancer Institute. The role of the media in promoting and reducing tobacco use. Tobacco Control Monograph No. 19. Bethesda, Md: Department of Health and Human Services, National Institutes of Health, National Cancer Institute, 2008. (NIH Pub. No. 07-6242.)

36 Durkin SJ, Biener L, Wakefield MA. Effects of different types of antismoking ads on reducing disparities in smoking cessation among socioeconomic subgroups. Am J Public Health 2009; 99: 2217-2223.

37 Borland R, Yong HH, Wilson $\mathrm{N}$, et al. How reactions to cigarette packet health warnings influence quitting: findings from the ITC Four-Country survey. Addiction 2009; 104: 669-675.

38 Yong HH, Borland R, Thrasher JF, et al. Mediational pathways of the impact of cigarette warning labels on quit attempts. Health Psychol 2014; 33 1410-1420.

39 Durkin S, Brennan E, Coomber K, et al. Shortterm changes in quitting-related cognitions and behaviours after the implementation of plain packaging with larger health warnings: findings from a national cohort study with Australian adult smokers. Tob Control 2015; 24: ii26-ii32.

40 Wakefield M, Coomber K, Zacher M, et al. Australian adult smokers' responses to plain packaging with larger graphic health warnings 1 year after implementation: results from a national cross-sectional tracking survey. Tob Control 2015 24: iil7-ii25.

41 Yong $\mathrm{H}-\mathrm{H}$, Borland R, Hammond D, et al. Smokers' reactions to the new larger health warning labels on plain cigarette packs in Australia: findings from the ITC Australia project. Tob Control 2015; 19 Feb [Epub before print]. doi: 10.1136/ tobaccocontrol-2014-051979.

42 Hill S, Amos A, Clifford D, Platt S. Impact of tobacco control interventions on socioeconomic inequalities in smoking: review of the evidence. Tob Control 2014; 23: e89-e97.

43 Wakefield MA, Brennan E, Durkin SJ, et al. Still a burning issue: trends in the volume, content and population reach of newspaper coverage about tobacco issues. Crit Public Health 2011; 21: 313-325.

44 Sweet MA. Social media: new links for Indigenous health. Med J Aust 2013; 199: 18.

45 Kim HS, Bigman CA, Leader AE, et al. Narrative health communication and behavior change: the influence of exemplars in the news on intention to quit smoking. J Commun 2012; 62: 473-492.

46 Nicholson AK, Borland R, van der Sterren AE, et al. Social acceptability and desirability of smoking in a national sample of Aboriginal and Torres Strait Islander peoples. Med J Aust 2015; 202 (10 Suppl): S57-S62. 